\title{
Are the asymmetries of the orthostatic posture random?*t
}

\author{
P.-M. GAGEY ${ }^{1}$, B. ASSELAIN², N. USHIO³, M.LECONTE', J.B. BARON ${ }^{4}$
}

\begin{abstract}
Three posture asymmetries and their connections were assessed by a statistical study as rigorous as possible on the subjects of a sample from a population considered as normal after negative criteria. The comparison of probabilities observed with random probabilities shows that there is less than one chance in a thousand to make an error by rejecting the hypothesis that the asymmetries of the orthostatic posture are random. The definition of the limits of these asymmetries thus fits in the search for the conditions of a clinical examination of the posture.
\end{abstract}

Keywords: Vestibule; Postural; Asymmetries

\section{INTRODUCTION}

The postures of the head and pelvis of a normal man in orthostatism are not symmetrical with respect to his sagittal intermalleolar vertical plane, the subject is inclined, turned on one side. The postural response to the occlusion of the eyes during the Romberg's maneuver is not symmetrical with respect to the same sagittal intermalleolar vertical plane: the subject deviates and turns in a certain direction ${ }^{(1-4)}$. All the observers do notice these asymmetries, but few take them into consideration, as if it were an unimportant element, meaningless, at the limit as a random thing. Following a logical approach, we thought it necessary to specify the level of truth we were at by giving importance to these asymmetries; we therefore sought to answer the following question: how many chances do we have to be wrong in accepting the hypothesis that these posture asymmetries are not random?

\section{MATERIAL AND METHODS}

In a population of normal men, described by a series of negative characters, we studied, on a sample, three random qualitative variables with two classes (inclination of the bipupillary axis, horizontal rotation of the pelvis, deviation during the Romberg's test and we compared the hypothesis of independence of these factors with the probabilities observed in order to be able to answer our question.

\section{DESCRIPTION OF THE POPULATION:}

To avoid still unknown interferences with pathological phenomena we have chosen a very restrictive set of criteria:

- subjects born after 1940

- Without a history of fracture of the lower limbs,

- no cervico-cranial trauma,

- No static disorders of the spine and pelvis, visible on clinical examination (pelvis landmarks at the same horizontal level, no horizontal rotation of the pelvis greater than $5^{\circ}$, no kyphosis seen in leaning posture)

- No genu valgum,

- No signs of minor vertebral derangement highlighted by the Maigne's technique ${ }^{(5)}$

- No oculomotor imbalance appearing clinically in the under-screen examination or in the convergence maneuver;

- No clinical involvement of the ears (no memorized otological history, audible signal of $4 \mathrm{KHz}$ received from on both sides at $15 \mathrm{dBA}$, no dizziness)

- No sign of suffering in the trigeminal area,

- Visual acuity $10 / 10$ far vision at the scale of Monoyer or Snellen; 1.5 near vision, at the scale of Parinaud. \footnotetext{
la posture orthostatique sont-elles aléatoires? Agressologie, 18, 277-283.

1 APAS, Paris

Full list of author information is available at the end of the article.

Financial support: nothing to declare
}

*Meeting of the Belgian French and Dutch sections of the posturography society. Louvain, March 26, 1977

'This paper has been first published in French thanks to Agressologie Journal: Gagey P.M. Asselain B., Ushio N., Leconte M., Baron J.B. (1977) Les asymétries de

Corresponding author: Pierre-Marie Gagey - Association de Posturologie Internationale - API, Paris, France. E-mail: pmgagey@gmail.com

Submission date 09 January 2019; Acceptance date 11 March 2019; Publication date 11 November 2019 


\section{Sample selection}

The choice of subjects was made by a person who was totally ignorant of this research, among the 4,000 subjects of the Building and Public Works of the Paris Region that we were to examine during the course of the year, according to historical and geographical standards unrelated to the posture of the subjects.

\section{The three random qualitative variables with two classes:}

Inclination of the bipupillary axis on the horizontal.

The horizontal inclination of the ideal line joining the two pupils, or bipupillary axis (BP), was examined using a grid placed between the subject and the observer, the level of the grid having been checked (Fig. 1) carefully. The subject was instructed to hold his head upright (subjective vertical). Only two answers were possible:
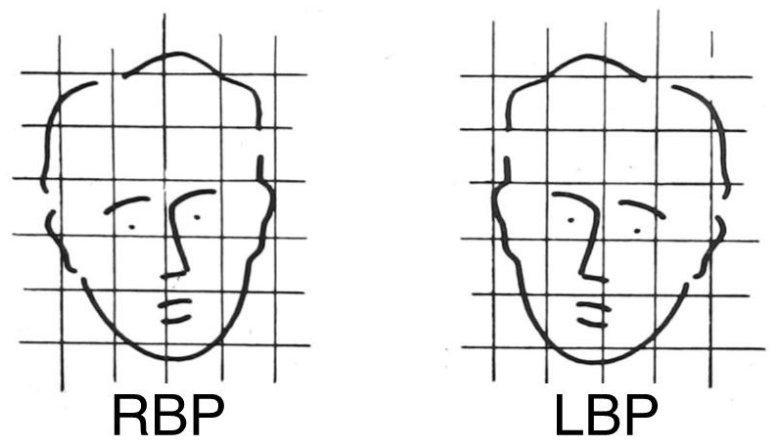

Figure 1. Inclination of the bipupillary axis on the horizontal.

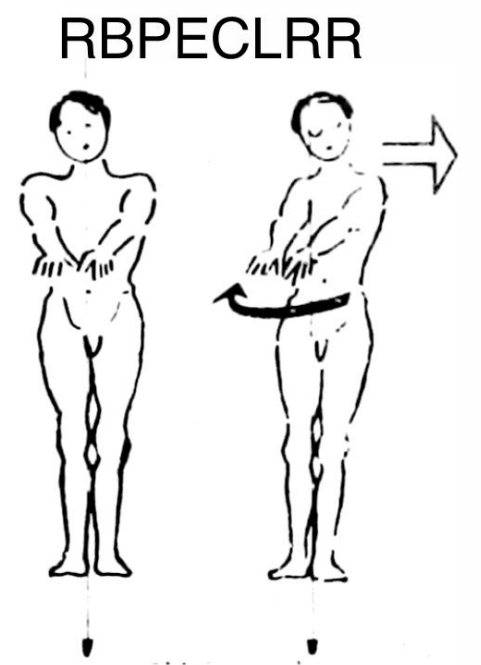

- Bipupillary axis inclined down and to the right: RBP,

- Bipupillary axis inclined bottom left: LBP.

Some relaxation movements were requested from the subject between two successive observations of the bipupillary axis.

\section{Deviation during the Romberg test.}

We make a small change to the classic position of the Romberg test: the subject holds his arms outstretched in front of him horizontally, hands overhand, firmly attached by their radial edge. Doing so, the deviation occurring at the occlusion of the eyes can be noted at two points of the subject: the base of the neck and the indexes (Figs 1 and 2). The movements identified at the base of the neck take place in the frontal plane of the subject and occur to the right or to the left:

- Eyes closed, deviation of the subject to his right: ECR,

- Eyes closed, deviation of the subject to his left: ECL.

The movements noted at the level of the indexes are the sum of the translation movements in the frontal plane, already described, and the rotational movements of the body about its vertical axis. Given this remark, the movements observed at the level of the indexes make it possible to note the direction of the rotation at the occlusion of the eyes:

- Rotation to the right: RR,

- Rotate to the left: LR.

We give the same value (see discussion) to the translational movement to the left and to the rotational movement to the right, just as we group in the same section the movements of

\section{LBPECRLR}

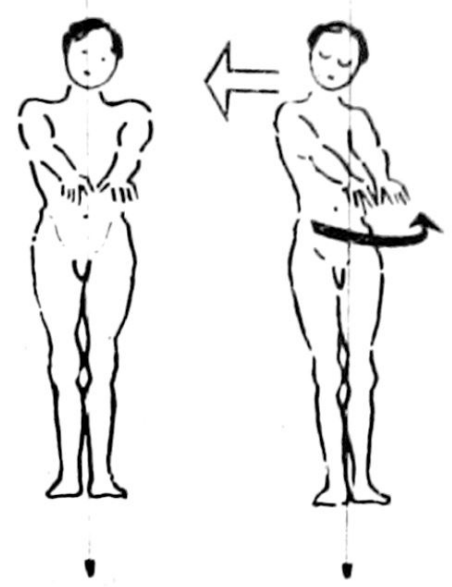

Figure 2. Deviation during the Romberg's maneuver.

Note: A mark at the base of the neck, another mark at the indexes to observe the translations and rotations that appear after the occlusion of the eyes. RBPECLRR: bipupillary axis inclined to the right: RBP, eyes closed: EC, the subject deviates on his left: $L$, and turns towards his right: RR.

LBPECRLR: bipupillary axis inclined to the left: LBP, eyes closed: EC, the subject deviates on his right: $R$, and turns towards his left: LR. 
translation to the right and of rotation to the left, so that only two responses were retained to the occlusion of the eyes:

- Translation to the right and/or rotation to the left: ECRLR,

- translation to the left and/or rotation to the right: ECLRR.

The answer impossible to determine, which is exceptional, was used only to calculate the number of subjects in the sample.

\section{Horizontal rotation of the basin:}

The rotation of the pelvis around the vertical axis of the subject, or rotation in the horizontal plane, was appreciated by means of a ruler held horizontally, and tangent to the gluteal masses of the subject. The angle made by this ruler with a shim tangent to the posterior edges of the heels was observed by simple sight and evaluated with the help of an angular scale glued to the platform on which the subject was standing (Fig. 3). The values of these angles were not retained and they were only observed to eliminate the subjects whose angle of rotation of the basin exceeded $5^{\circ}$.

Only two answers were possible:

- Horizontal rotation of the pelvis bearing the right side forward: R,

- Horizontal rotation of the pelvis with the left side forward: $L$.

\section{RESULTS}

950 subjects were examined to obtain a sample of 105 normal subjects according to the criteria adopted.

\section{Distribution of the variables taken in isolation.}

\section{Bipupillary axis:}

- right axis (RBP): 62 subjects, or $60.95 \%$,

- left axis (LBP): 41 subjects, or $39.05 \%$.
Deviation to the test of ROMBERG:

- Translation to the right and/or rotation to the left (ECRLR): 46 subjects, $43.80 \%$.

- Translation to the left and/or rotation to the right (ECLRR): 57 subjects, or $54.28 \%$.

- Impossible to determine: 2 subjects.

\section{Horizontal rotation of the pelvis:}

- Right side forward (R): 56 subjects, 53.33\%,

- Left side forward (L) 49 subjects, $46.66 \%$.

Since the conditions of validity are satisfied ( $n p$ and $n q$, products of the population by the probability being greater than 10), we can estimate that the distribution of the frequencies observed, $f$, follows a normal distribution and consequently that the interval of confidence of the real frequency, $F$, for alpha $=0.03$ is given by the formula:

$$
F= \pm 2,17 \sqrt{\frac{f(1-f)}{105}}
$$

The limits of the $97 \%$ confidence interval are therefore for each variable:

- RBP (bipupillary axis inclined to the right: $61 \pm 10 \%$,

- LBP (bipupillary axis inclined to the left): $39 \pm 10 \%$,

- ECRLR (right translation, left rotation): $44 \pm 10 \%$,

- ECLRR (right translation, left rotation): $54 \pm 10 \%$,

- R (right buttock forward): $53 \pm 10 \%$,

- L (left buttock forward): $47 \pm 10 \%$.

\section{Linking variables taken two by two.}

Between the taken two-by-two variables, we can draw up the frequency distribution tables observed (Tables 1, 2 and 3):
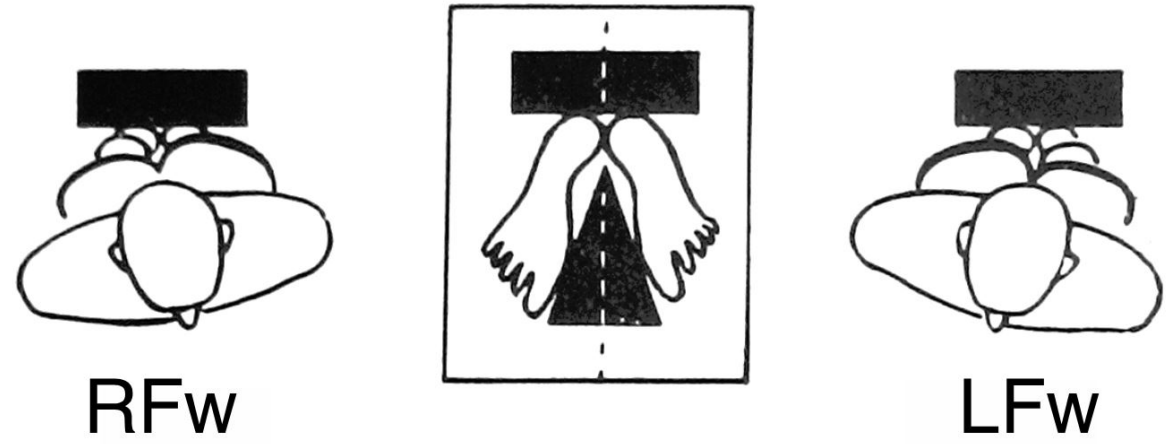

Figure 3. Horizontal rotation of the pelvis.

Note: In the center, the observation platform (the angular scale is not figured), of each side: RFw: the right buttock is forward, LFw: the left buttock is forward. 


\section{Connections observed between the three variables.}

Each of the 105 subjects observed could be located in one of the columns of a dichotomous table showing the probability of observation of the different possible combinations of the three variables (Table 4).

\section{Meaning of the observed CONNECTIONS}

Assuming that the three variables are independent, the probability $\mathrm{P}$ of finding them grouped on the same subject is equal to the product of their respective frequencies, $f$. For the case "RBP, ECLRR, R" we can write, under the assumption of independence of the three variables:

$P(R B P, E C L R R, R)=f(R B P) \times f(E C L R R) \times f(R)=0.174$

However, the observed probability is:

$p(R B P, E C L R R, R)=0.39$.

Table 1. CONTINGENCY BETWEEN THE INCLINATION OF THE BIPUPILLARY AXIS (RBP, LBP) AND THE MOVEMENTS OBSERVED DURING THE ROMBERG TEST (ECRLR, ECLRR). [[Q1: Q1]]

\begin{tabular}{lccc}
\hline & LBP & RBP & \\
\hline ECRLR & 39 & 7 & 46 \\
ECLRR & 2 & 55 & 57 \\
& 41 & 62 & 103 \\
\hline
\end{tabular}

Note: $\mathrm{Chi}^{2}=70.14$, Degree of significance $\mathrm{p}<0.001$.

Table 2. CONTINGENCY BETWEEN THE INCLINATION OF THE BIPUPILLARY AXIS (RBP, LBP), AND THE HORIZONTAL ROTATION OF THE BASIN (R, L)

\begin{tabular}{cccc}
\hline & LBP & RBP & \\
\hline $\mathrm{R}$ & 10 & 45 & 55 \\
$\mathrm{~L}$ & 31 & 17 & 48 \\
& 41 & 62 & 103 \\
\hline
\end{tabular}

Note: $\mathrm{Chi}^{2}=23, \mathrm{p}<0.001$

Table 3. CONTINGENCY BETWEEN THE MOVEMENTS OBSERVED DURING THE ROMBERG TEST (ECRLR, ECLRR) AND THE HORIZONTAL ROTATION OF THE BASIN(R, L)

\begin{tabular}{cccc}
\hline & ECRLR & ECLRR & \\
\hline $\mathrm{R}$ & 14 & 41 & 55 \\
$\mathrm{~L}$ & 31 & 17 & 48 \\
& 46 & 57 & 103 \\
\hline
\end{tabular}

Note: $\mathrm{Chi}^{2}=17.62 ; \mathrm{p}<0.001$.
Given that in each class the probabilities are greater than 10 we can estimate that the frequencies follow approximately a reduced normal distribution, that is to say that the confidence limits Uc to reject the hypothesis of independence of these three variables are:

Degree of significance: better than $1 \%$. Which means that by accepting the assumption that RBP, ECLRR, R are not independent we have less than one chance in a thousand to be wrong. The degree of significance is identical for the cases LBP, ECRLR, L.

\section{DISCUSSION.}

If the results presented do not make it possible to say anything else than: " the observed asymmetries of the orthostatic posture are not random " at least they incite to seek a law of organization of these asymmetries of postures.

\section{Towards a law of organization of the asymmetries of the orthostatic posture.}

In our perspective of posture analysis according to its asymmetries with respect to the vertical sagittal plane, we are led to speak of a right-left duality, at the level of the regulatory centers of the postural tonic activity, to adopt some principle such as this ancient notion of "Vestibular tone" right and left. To avoid confusion we will choose the name of "postural vestibular polarity" proposed by Hirahawa ${ }^{(8)}$. It is known that the tone of the extensor and abductor muscles of the lower limbs is under the control of the ipsilateral centers, and that the tone of the lateral flexor muscles of the spine is dependent on the contralateral centers. Using these data we can analyze the observed facts as follows:

a) Subject having the bipupillary axis inclined to the right, the pelvis in slight horizontal rotation bearing the right side forward, and, in the Romberg test, presenting a translation to the left in the frontal plane and a rotation to the right around its vertical axis (RBP, ECLRR, R). The inclination of the head to the right connotes a slight relative hypertonia of the right flexors of the cervical spine (Fig 4, left part), a certain left postural vestibular polarity.

The rotation of the pelvis, which carries the right side forwards, connotes a discreet opening of the angle of the left tibiotarsal articulation, that is to say a slight relative hypertonia of the extensors of the left lower limb (Fig. 4, left), a certain left postural vestibular polarity.

Table 4. Meaning of observed links

\begin{tabular}{|c|c|c|c|c|c|c|c|c|c|c|c|c|}
\hline & RBP & LBP & & & & & & & & & & \\
\hline & ECLRR & ECRLR & & & & & & & & & & \\
\hline & $\mathbf{R}$ & $\mathbf{L}$ & $\mathbf{R}$ & $\mathbf{L}$ & $\mathbf{R}$ & $\mathbf{L}$ & $\mathbf{R}$ & $\mathbf{L}$ & $\mathbf{R}$ & $\mathbf{L}$ & $\mathbf{R}$ & $\mathbf{L}$ \\
\hline $\mathrm{n}=$ & 41 & 14 & 4 & 3 & 1 & 1 & 29 & 10 & 2 & 0 & 0 & 0 \\
\hline$p=$ & 0.39 & 0.13 & 0.038 & 0.028 & 0.009 & 0.009 & 0.276 & 0.095 & 0.019 & 0 & 0 & 0 \\
\hline
\end{tabular}



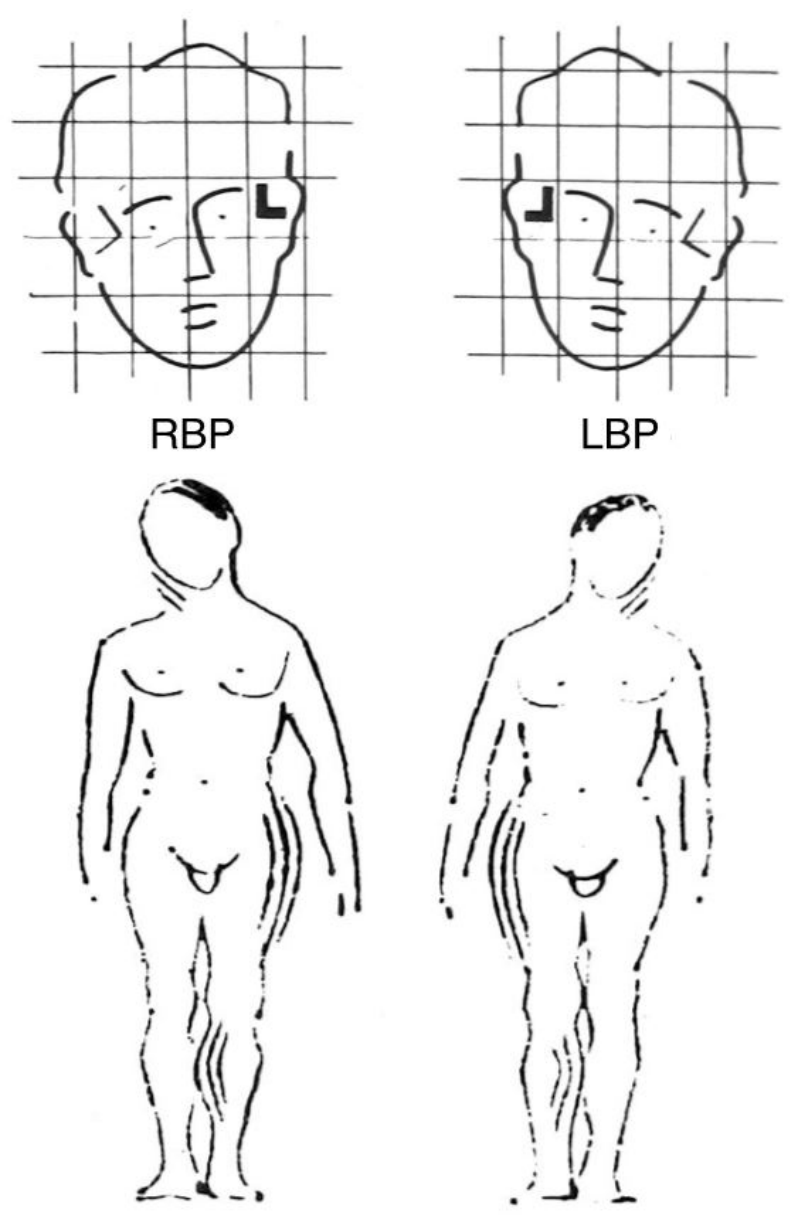

Figure 4. The asymmetries of the orthostatic posture connote a discreet relative hypertonia of certain muscle groups (double contour on the patterns); this systematized relative hypertonia manifests a functional vestibular polarity which, curiously, has the effect of placing the functionally dominant labyrinth in the external reference planes, vertical and the horizontal, those provided by the visual afferences.

Curiously this left postural vestibular polarity has the effect of placing the horizontal canal and the anterior vertical canal of the left labyrinth in the reference planes of the vertical and horizontal exteriors ${ }^{(10)}$, those provided by visual afferences (Fig. 4, left-hand part).

During the Romberg maneuver, during the occlusion of the eyes, everything happens as if this left postural vestibular polarity disappeared and the influence of the right centers reappears causing:

- a slight increase in the tone of the abductors of the right lower limb which causes, the translational movement to the left in the frontal plane

- a slight increase in the tone of the extensors of the right lower limb which discreetly opens the angle of the right tibio-tarsal joint, therefore pushes the right buttock back by operating a horizontal rotation movement of the pelvis about its vertical axis, rotation which appears at the index level as a movement to the right. b) An identical analysis could be made of the symmetrical LBP, ECRLR, L posture (Fig. 4, right).

The interpretation we give of these posture asymmetries is not in opposition with the remarks of Aubry et al. (6), Lacour, Bonnet and Roll (7), Hirasawa (8), Hoogmartens and Stuyck (9), but it needs further research.

\section{Normality criteria.}

The two combinations RBPECLRR, R and LBPECRLR, L alone represent $66 \%$ of the cases observed, compared to $33 \%$ for the other six possible combinations: we therefore tend to consider them as representative of the normal organization.

But the CONNECTION is much stronger between the inclination of the bipupillary axis (RBP, LBP) and the movements observed during the Romberg test (ECLRR, ECRLR). Let us recall that its $\mathrm{Chi}^{2}$ equals 70.14. This connection is so strong that we call normal the following two reactions observed during the Romberg test:

- RBPECLRR,

- LBPECRLR.

That is to say, these movements are contralateral to the inclination of the head for translation in the frontal plane, homolateral to the inclination of the head for rotations in the horizontal plane. And this normality is at the level of the phenomenon, whatever its interpretation.

\section{Critique}

Two inflexible criticisms can be made about this work. The reference population is only the population of construction and public works workers in the Paris region, defined as normal by the end of the criteria adopted. The observed sample is not strictly random. There are two possible biases that can only be overcome by the implementation of more important means than those we have at our disposal.

\section{CONCLUSION}

Having for some years focused our attention on the asymmetries of the orthostatic posture and sought to formulate some laws that could be used in a postural clinical examination, we thought that it was desirable to fix the possible margins of error of our fundamental hypothesis: the asymmetries of orthostatic posture are not random.

By a statistical study as rigorous as possible, three posture asymmetries and their connections to the subjects of a sample from a population considered normal at the end of a series of negative criteria were assessed.

The comparison of the probabilities observed with the random probabilities provides a satisfactory figure: there is less than one chance in a thousand that the asymmetries of the orthostatic posture are random. 


\section{AUTHOR'S CONTRIBUTIONS}

All authors contributed equally to this study.

\section{CONFLICT OF INTEREST:}

nothing to declare.

2 Centre de calcul. CHU Pitié-Salpétrière, Paris;

3 Département ORL, Université de Tokushima, Japon;

${ }^{4}$ Laboratolre de posturoqrapnle, hôpital Sainte-Anne Paris.

\section{REFERENCES}

1. Baron J. Muscles moteurs oculaires et équilibration. Arch hospital. 1957;29(2):51-2.

2. Baron J. Données récentes sur l'équilibration er le vertige. Rev psychol franç. 1959;4(3):205-11.

3. Soulairac A, Baron J, Quetin M. L'importance des troubles oculomoteurs dans certains types de déséquilibres posturaux, A propos d'une dépression hypochondriaque à point de départ oculomoteur. Ann Médpsyched. 1957;3:1-4.
4. Soulairac A, Baron J, Filliozat R, François R, Canonne M, Paris J, et al. Importance des troubles de la régulation posturale d'origine oculomotrice dans certains cas de syndromes 'subjectifs post-commotionnels et leur objectivation clinique. Rev, Neurol. 1965;112(6):531-8.

5. Maigne R. Diagnostic et mécanisme d'un dérangement intervertébral mineur. Cinésiologie. 1973;12(47):25-48.

6. Aubry M, Pialoux P, Burgeat M, Danon J, Fontelle P, Heuleu J, et al. Étude d'une méthode d'explorations fonctionnelles des syndromes vestibulaires par l'association de l'électronystagmographie, de l'électromyographie et de la statokinésimétrie, . Acta Otolaryng (Stockholm). 1968;65:154/60.

7. LacouR M, Bonnet M, Roll J. Effets spinaux de stimulations vestibulaires chez l'homme normal, mise en évidence d'une dominance vestibulaire. Agressologie. 1973;14(B):57-8.

8. Hirasawa Y. Study of human standing ability by multipoini.XY-Tracker and pedoscope. Agressologie. 1976;17(B):21-7.

9. Hoogmartens $M$, Stuyck J. First results with vibration electromyography as a differential measurement of the postural tone in the left and right spinal muscles. Agressologie. 1977;18(6):341-3.

10. Blanks RHI, Curthoys IS, Markhan $\mathrm{CH}$. Plantar relationships of the semicircular canals in man. Acta Laryngol. 1975; 80: 185-96. 